\title{
Caracterización arqueométrica de pigmentos y soportes procedentes de pinturas murales góticas (S. XIII-XV)
}

\author{
A. KRIZNAR*, J. HÖFLER**, A. RUIZ-CONDE*, P.J. SANCHEZ-SOTO*x \\ *Instituto de Ciencia de Materiales de Sevilla (ICMSE), Centro Mixto CSIC-US, c/Américo Vespucio $\mathrm{n}^{\circ}$ 49, Centro de Investigaciones Científicas Isla \\ de la Cartuja, Centro Mixto CSIC-US-Junta de Andalucía, Isla de la Cartuja, 41092-Sevilla \\ **Departamento de Historia del Arte, Facultad de Filosofía, Universidad de Ljubljana, Askerceva 2, 1000-Ljubljana (Eslovenia)
}

\begin{abstract}
El presente trabajo forma parte de una investigación más amplia sobre pinturas murales góticas (S. XIII-XV). En concreto, se han estudiado las que se encuentran en el interior de varias iglesias de Eslovenia y que no habían sido estudiadas, hasta la fecha, por medio de técnicas instrumentales de análisis de materiales. Una de ellas está situada en la ciudad de Crngrob (Eslovenia) y se ha seleccionado como objeto de este estudio (Iglesia de la Anunciación de María). El estudio científico de las muestras en el ICMSE se basó, principalmente, en la preparación de una serie de secciones estratigráficas a partir de los fragmentos pequeños de las mismas para analizar las diferentes capas de mortero soporte y de la propia pintura. Se examinaron dichas preparaciones por varias técnicas, como son fotografía digital, microscopías óptica y electrónica (MEB), espectroscopía IR (reflexión) y EDX. Una información adicional sobre pigmentos y morteros se obtuvo mediante IR (transmisión), preparando pastillas con $\mathrm{KBr}$, además de DRX.

Las muestras estudiadas pueden clasificarse en dos grupos que, a su vez, permiten apreciar dos formas de pintura mural. La primera es típica para pintura italiana gótica: fresco buono sobre varias capas de mortero, con empleo de polvo de mármol para hacerlo más liso y blanco. Los resultados obtenidos han permitido caracterizar e identificar los morteros y pigmentos inorgánicos empleados y que son apropiados para pinturas murales. A título de ejemplo, se han empleado óxidos de hierro para amarillo, naranja, rojo y verde, pero no se ha encontrado malaquita ni existen indicios de compuestos de cobre para el color verde. En capas más antiguas se ha encontrado cinabrio para el color rojo, típico de Italia. Las pinturas fueron realizadas sin emplear otro aglutinante que la propia cal procedente del mortero. Estas características y el empleo de cinabrio, sitúan las pinturas del 1400-1410 en la corriente artística italiana del Trecento. La segunda manera es típica del norte de Europa: técnica de una o dos capas de mortero, con una capa fina de cal superpuesta para dar mayor fuerza a la cal del mortero como aglutinante.

Teniendo en cuenta los resultados obtenidos en este estudio sobre los dos tipos de muestras estudiadas, se concluye que las corrientes italiana y norteeuropea se encontraron en territorio esloveno, lo que se aprecia tanto desde el punto de vista estilístico como científicamente. Investigaciones en esta temática ayudan a conocer mejor tanto el Arte de Europa Central y el de Eslovenia con la zona adriática, como el mapa general del Arte Europeo en el tiempo de la Edad Media.
\end{abstract}

Palabras clave: arqueometría, pigmentos, pinturas murales, gótico, cinabrio, morteros, Patrimonio Cultural, Historia del Arte

Archaeometric characterization of pigments and mortars from Gothic wall paintings (13-15th Centuries)

A novel investigation on samples of gothic wall paintings (13-15th Centuries) has been carried out. They were found in some Churchs of Slovenia, being not yet studied using technics of materials analysis. One of them is selected: the Church of "Anunciación de María", city of Crngrob, Slovenia. The scientific investigation of the Gothic wall painting samples was mainly based in the preparation of the so-called stratigraphic sections (cross-sections) from the original small samples. This procedure allows to study the different layers of mortar as support and the painting itself. Next, these preparations were examined using several instrumental techniques commonly applied in materials characterization at the ICMSE, for instance, digital photography, optical and electronic microscopies, IR spectroscopy and EDX for chemical analysis. Aditional information concerning pigments and mortars was obtained by IR transmision spectroscopy using $\mathrm{KBr}$ pellets, as well as using XRD.

Samples studied at the ICMSE can be classified in two groups, which allows to appreciate two procedures or techniques of wall paintings performed at the Church of Crngrob. The first is typical of Gothic Italian paintings: technic of so-called fresco buono over several layers of mortars, using marble powder to get a white and smooth surface.

The results of the present study have also allowed to characterize and identify the inorganic pigments and mortars used in these wall paintings. They were found to be the appropiate for this kind of technical work. For instance, they have been applied iron oxides to get the yellow, orange and even green colours, but surprisingly it has not been found neither malachite (copper pigment of green colour) nor copper compounds to get a green colour. In older layers of wall paintings, the pigment cinnabar was used to get the red colour. It is a mineral used typically in Italy. As revealed in this research, no aglutinant except the lime coming from the mortar as support were used in these Gothic wall paintings. Moreover, this feature, besides of cinnabar application, allows to establish the 1400-1410 wall paintings in the artistic Italian current named Trecento. The second procedure to paint is a typical of North Europe: one or two layer of mortar with a fine layer of lime. This is used to improve the strenght of lime as an aglutinant in the mortar.

With this study, it is concluded that the Italian and North-European artistic currents met in Slovenian territory, which is appraisable as much stilistic (Art History) as scientific (Chemical and Physical analysis) point of views. This kind of investigation allows to know better the Central European Art and the Slovenian Art in the Adriatic zone, as well as the general map of European Art in the Middle Age. 


\section{INTRODUCCIÓN}

\subsection{Estudios científicos sobre materiales del Patrimonio Cultural}

Las técnicas instrumentales de análisis de materiales han facilitado la investigación de ciertos aspectos del pasado (1-3). De ahí ha surgido una nueva disciplina que se ocupa de la Física y la Química de la Arqueología, denominada "Arqueometría" y, en general, de estudios aplicados del Patrimonio Histórico-Artístico y Bienes Culturales englobados dentro de lo que se considera "Patrimonio Cultural" (4-6). La idea que subyace en este concepto es tratar de estimular una cooperación multidisciplinar entre las Ciencias Humanísticas y las Ciencias Experimentales. No sólo es necesaria la colaboración conjunta de los propios historiadores y arqueólogos con los físicos, geólogos y químicos, sino que es imprescindible contar con especialistas en una gran variedad de materiales, como son los cerámicos y vítreos, además de disponer inicialmente de una serie de técnicas específicas de investigación y estudio. Ello es cada vez más patente por el cúmulo de información que las técnicas instrumentales suministran y, lo más importante, para interpretar los resultados, adquiriendo esta cooperación un reconocimiento cada vez mayor en el ámbito científico (4-6).

En este caso particular, el estudio de pigmentos empleados en pinturas murales es de sumo interés. Así, al inicio de este trabajo se han planteado varios objetivos. En primer lugar, poner de manifiesto la riqueza del Arte gótico que se da en países europeos. En segundo lugar, exponer una serie de resultados de interés sobre análisis realizados con muestras de pinturas góticas empleando diversas técnicas instrumentales para la caracterización de materiales. Dichas técnicas, la mayoría no destructivas, ya vienen siendo habitualmente utilizadas en diversas cooperaciones que se llevan a cabo entre Historiadores del Arte, Profesionales de las Bellas Artes, Físicos, Geólogos y Químicos, entre otros $(5,6)$. De este modo, se trata de conocer la naturaleza y características de los pigmentos empleados y, en consecuencia, poder realizar un diagnóstico del estado de conservación de las pinturas con vistas a su posible restauración. Por tanto, los resultados obtenidos son de valiosa utilidad para conservadores y restauradores que deberían intervenir rigurosamente, en una etapa final, para la preservación de los Bienes Culturales como herencia para las generaciones futuras.

\subsection{Antecedentes históricos}

El Departamento de Historia del Arte de la Universidad de Ljubljana (Eslovenia) inició una serie de estudios desde una perspectiva histórico-artística sobre pinturas murales góticas de la rotonda de Selo (Prekmurje), en el noreste de Eslovenia (7). Estos trabajos se realizaron en conexión con la pintura del mismo tiempo de la Europa Central, trabajo que fue galardonado con el Premio universitario Preseren. La colaboración entre este Departamento universitario junto con el Ministerio de Ciencia, Educación y Deporte de Eslovenia hizo posible la continuación de estas investigaciones sobre pinturas murales de 1400 , con especial atención al denominado "taller de Duques"(8). Dicho taller trabajaba para los Habsburgo y la nobleza de su corte. De este modo, se compararon estilísticamente las obras de
Eslovenia, Austria, Italia y República Checa y se iniciaron estudios físico-químicos de las mismas.

El estudio de pinturas murales góticas se ha centrado en diversos monumentos del Patrimonio Cultural de Eslovenia. Como objeto del presente trabajo, se han seleccionado las pinturas murales de la iglesia de la Anunciación de María en Crngrob (Eslovenia) que fue una de las iglesias de romería más importantes en Eslovenia (9). Probablemente la construyeron como edificio de una nave ya al final del siglo XIII, pero en los siglos siguientes sufrió varios cambios arquitectónicos. Hoy en día se muestra como basílica de tres naves, con un gran coro realizado en 1520 por el denominado maestro Jurko. En el interior y en la fachada de la iglesia se encuentran varias pinturas murales que sitúan a esta iglesia de Crngrob entre los monumentos más importantes y destacados del Patrimonio Cultural de Eslovenia. Es necesario mencionar que las pinturas murales en el coro todavía quedan por descubrir, mientras que las de las naves representan trabajos de diferentes épocas y estilos. La parte más antigua se encuentra en la pared norte. Es de principios del siglo XIII y representa la vida de la Virgen. En la misma época fue pintada también una escena de Crucifixión en la parte baja. Entre 1400 y 1410, un taller pictórico de Furlania (Italia), perteneciente al taller de S. Lorenzo de Skofja Loka, pintó en un estilo post-giottesco el ciclo de la Pasión de Cristo encima de escenas de la vida de la Virgen situadas en la parte superior de la misma pared.

En el año de 1453, apareció en Crngrob uno de los pocos pintores conocidos por su nombre en la época. Se trataba del llamado maestro Bolfgang, de raíces norteeuropeas. Con aires renovados de un nuevo estilo más realista, nacido en el siglo XV en el norte de Europa y con la ayuda de los gráficos del así llamado "maestro E.S." que le servían de apoyo en las composiciones y figuras, el maestro Bolfgang pintó encima de los frescos del siglo XIII y principios del XV. Las escenas conservadas en la iglesia de la Anunciación de María representan la Natividad, la Adoración de los Reyes Magos y a San Wolfgang. En el año de 1464, este maestro Bolfgang volvió al mismo lugar, donde en la fachada de la iglesia dejó pintada la imagen de San Cristóbal. Antes de esta fecha, entre 1370-1380, la fachada ya había sido decorada por un autor italiano anónimo con escenas del ciclo de la Pasión de Cristo. En 1460 realizó trabajos allí el taller de otro pintor esloveno, conocido con el nombre de Janez Ljubljanski (Juan de Ljubljana), que dejó la imagen del denominado Domingo Santo.

\subsection{Objetivos del estudio}

Hasta la fecha no se habían realizado estudios físicoquímicos en profundidad sobre estas pinturas murales, de ahí también su interés. El presente trabajo es una parte importante de la Tesis Doctoral de la primera firmante del artículo, titulada "Estilo y técnicas de las pinturas murales de la Edad Media en Eslovenia", quien ha venido realizando esta labor durante una estancia de seis meses (de Diciembre de 2002 a Mayo de 2003) en el Instituto de Ciencia de Materiales de Sevilla (ICMSE), Centro Mixto CSIC-US, becada por el Ministerio de Asuntos Exteriores de nuestro país. Esta estancia predoctoral de una Historiadora del Arte ha sido en cooperación con Químicos y Geólogos, dentro de un grupo de investigación del ICMSE incluido en la Red Temática de Patrimonio Histórico y Cultural (RTPHC) del CSIC, constituida en Octubre de 2001. 
Con los análisis realizados en estas investigaciones se conocerá la naturaleza química de los pigmentos utilizados en las pinturas murales, los posibles aglutinantes, así como el tipo, estructura y número de capas de morteros. De este modo, los resultados obtenidos revelarían con mayor seguridad la técnica utilizada en las pinturas elegidas en el muestreo (técnicas "a fresco" o "a secco"). Ello haría posible conocer con mayor precisión las diferentes influencias artísticas del Sur y Norte de Europa que se encontraron en el territorio de Eslovenia, lo que también ayudaría a conocer mejor tanto el Arte de Eslovenia y Arte de Europa Central con la zona adriática, como el mapa general del Arte Europeo en el tiempo de la Edad Media..

\section{EXPERIMENTAL}

\subsection{Muestras estudiadas de pinturas y soportes}

En el estudio llevado a cabo, se han analizado las pinturas del interior de la iglesia, pertenecientes al taller de Furlania ya mencionado en el apartado anterior, así como aquéllas atribuidas al maestro Bolfgang, segundas superpuestas a las otras. Se han intentado distinguir posibles diferencias en la técnica pictórica y los pigmentos utilizados, así como en la composición de los soportes y morteros. Una serie de muestras representativas se tomaron de fragmentos de frescos (pinturas y morteros de soporte), caídos de los muros durante los trabajos de descubrimiento y restauración realizados en 1935 y que ahora se conservan en el Departamento de Historia del Arte, Facultad de Filosofía, de la Universidad de Ljubljana (Eslovenia). Además, se han realizado diversas tomas de muestras in situ que también se han incluido en este estudio más general.

\subsection{Técnicas y métodos experimentales utilizados}

La parte más importante del estudio científico de las muestras de pinturas góticas de las que se dispone, en su estado original, se ha basado en la preparación de una serie de lo que se denominan en Restauración-Conservación "secciones estratigráficas" ó "estratigrafías", obtenidas con sumo cuidado y atención a partir de trozos muy pequeños de dichas muestras y que sean representativas. Se han realizado incluso varias preparaciones de las mismas para apreciar y estudiar distintos detalles. Todo ello ha permitido observar las diferentes capas de mortero (soporte) y pintura.

La preparación de estratigrafías se lleva a cabo en varias etapas utilizando una barra de metacrilato de unos $10 \mathrm{~cm}$, cortadas de una plancha de este material $(8-10 \mathrm{~mm}$ de espesor) y en la cual se han taladrado (con broca de 8 $\mathrm{mm}$ ), en su longitud, diversos conos muy próximos entre sí, sin perforar completamente el metacrilato. Previa limpieza de restos de operaciones previas, mediante unas pinzas y cuidadosamente, se colocan las muestras (tamaño ca. $2 \mathrm{~mm}$ o incluso inferior) dentro de estos conos y se añade una resina acrílica incolora en polvo junto con el catalizador líquido para embutirlas. El conjunto se deja estar varias horas y se procede al corte de cada cono con firmeza y despacio, para evitar que el rozamiento y el calor ocasionen posibles daños. Este corte es preferible realizarlo manualmente con una sierra pequeña. En el corte se sigue una dirección del mismo que pueda ofrecer, en principio, más información sobre las características del soporte y la pintura. En general, se procede al corte de forma perpendicular y próxima a la muestra para conseguir obtener el espesor real de los estratos y también pulir lo menos posible, siempre en seco y evitando contaminaciones que falsearán los resultados, primero con lija de carburo de silicio de grano 400 y después 1200, finalizando con un pulido con paño o fieltro de hilo colocado sobre una superficie lisa y fija. Por su interés, se remite a un artículo más técnico sobre aspectos prácticos del análisis de estratos en obras del Patrimonio Cultural donde se describe con todo detalle este procedimiento sobre preparaciones estratigráficas (10).

Las preparaciones estratigráficas (tamaño ca. $10 \mathrm{~mm}$ de largo) se examinaron por distintas técnicas instrumentales, como son microscopía óptica (Olimpus) con fotografía digital (cámara Nikon Coolpix), espectroscopía de infrarrojos (IR, equipo Nicolet TFIR provisto de microscopio de infrarrojos), microscopía electrónica de barrido (MEB, equipo JEOL JSM5400) y análisis químico por energías dispersivas de rayos X (EDX, Oxford Link con detector Si-Li acoplado al equipo de MEB). Para el estudio de muestras con estas dos últimas técnicas, se recubrieron las estratigrafías con una fina capa de oro (metalización) para hacerlas conductoras y facilitar el examen por MEB. En consecuencia, la preparación de estratigrafías posibilita un examen por distintas técnicas instrumentales de análisis de materiales, con la ventaja de que los resultados que se obtengan estarán, en este caso, asociados a la localización de los materiales en el contexto estratigráfico de los distintos fragmentos $(1,2,5,10)$.

Por otra parte, también es de interés conseguir una información adicional mediante espectroscopía IR (equipo Nicolet TFIR) por transmisión. Se han preparado pastillas a partir de una pequeña cantidad de muestra $(1 \mathrm{mg})$, en la mayoría de los casos sólo de los pigmentos separados, y de bromuro potásico $(300 \mathrm{mg})$. Asimismo, cuando la cantidad disponible de muestra lo permitía, se ha empleado la técnica de difracción de rayos X (DRX, Siemens D-501) para el examen de algunas muestras, generalmente atribuidas a morteros, que se han molido finamente en mortero de ágata. De este modo se ha realizado un estudio de las fases cristalinas presentes.

En definitiva, como ya se ha mencionado anteriormente, con los análisis realizados se pretende conocer la naturaleza química de los pigmentos utilizados en las pinturas murales y los posibles aglutinantes, así como conseguir más información sobre aspectos todavía inéditos de estas pinturas góticas.

\section{RESULTADOS OBTENIDOS Y DISCUSIÓN}

Las muestras analizadas se pueden clasificar en dos grupos: (a) Primer grupo: las pertenecientes a la capa pictórica fechadas en los años 1400-1410 y (b) Segundo grupo: las otras pertenecientes a la obra del maestro Bolfgang, mencionado en los antecedentes históricos incluidos en el apartado de introducción, fechadas en 1453.

El estudio de las preparaciones estratigráficas ha permitido realizar un examen del conjunto de pinturas murales investigadas a partir de una serie de muestras. A efectos ilustrativos del primer grupo de muestras, en la Figura 1 se incluye una preparación estratigráfica representativa que corresponde a una muestra extraída de la capa pictórica más externa, datada en 1400-1410, examinada con el microscopio óptico. Esta preparación permite apreciar el mortero soporte 


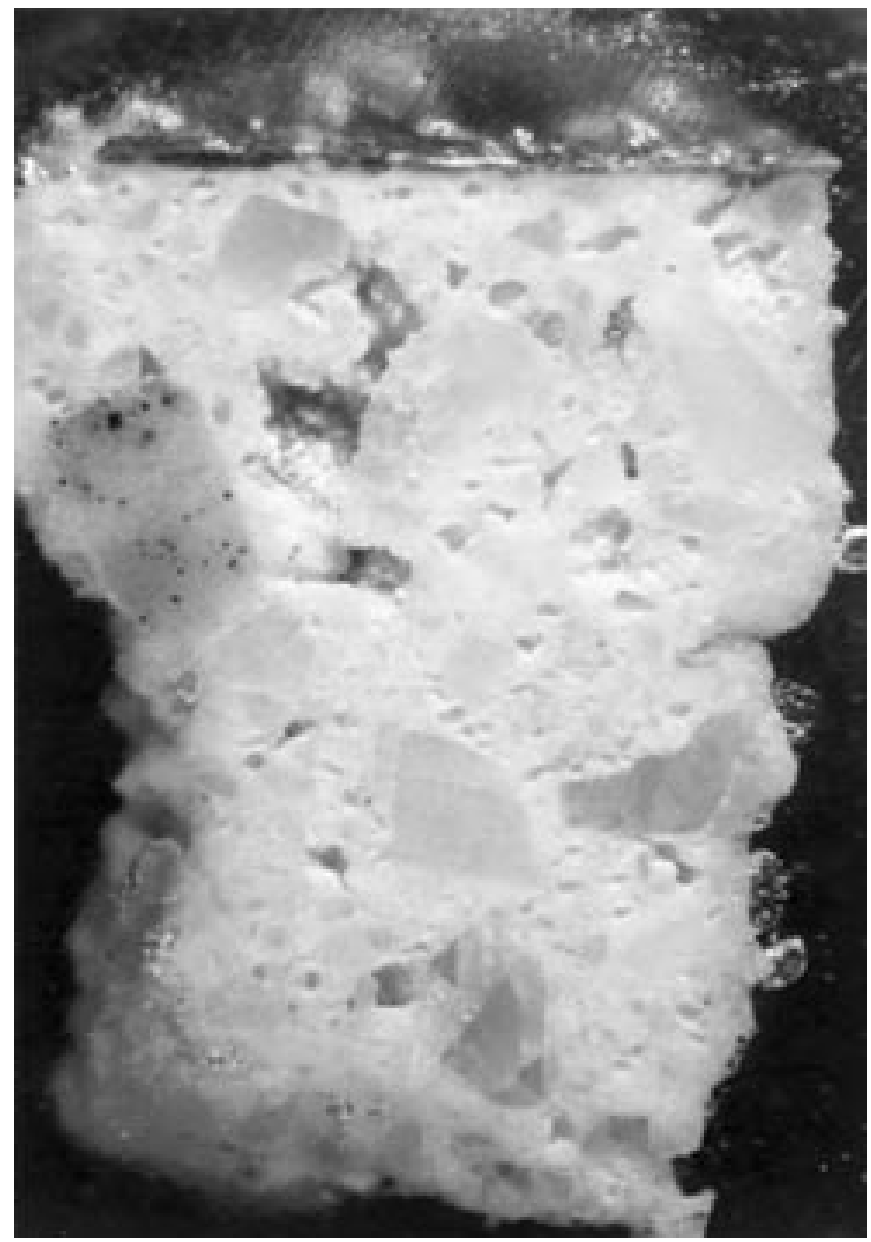

Fig. 1- Preparación estratigráfica (estratigrafía) correspondiente a la muestra CRG 8 (x60), procedente de la capa pictórica de 1400-1410 de pintura mural gótica de la iglesia de la Anunciación de María en Crngrob (Eslovenia).

de un espesor aproximado de unos 3-5 $\mathrm{mm}$. como una composición con granos de color blanco. En un principio y atendiendo a criterios artísticos sobre empleo de soportes y morteros en la época en la cual se datan estas pinturas, sin otros resultados físico-químicos que lo confirmaran, esta composición se atribuyó a una posible mezcla entre cal con polvo de mármol. Sobre esta capa de mortero preparado se pueden observar dos capas pictóricas: una de color verde (tierra verde) y otra de color rojo (ocre quemada).

En la Figura 2 se presenta otra estratigrafía representativa del segundo grupo. En este caso corresponde a una muestra extraída de la capa pictórica perteneciente al maestro Bolfgang y que se enmarca en el segundo grupo de muestras estudiadas. Las diferencias entre ambos grupos de muestras pictóricas se aprecian ya en cuanto al mortero. De acuerdo con los resultados del presente estudio, las pinturas correspondientes a muestras del primer grupo han sido realizadas empleando primero dos capas de mortero; la capa superior está compuesta por cal y carbonato cálcico. Ninguno de los análisis ha mostrado la presencia de silicatos y en este tipo de mortero no se ha encontrado arena silícea ("granos de arena", cuarzo, $\mathrm{SiO}_{2}$ ). Análogamente al caso anterior (Fig. 2), sobre el soporte de mortero presumiblemente compuesto de cal y arena, se observa una capa pictórica amarilla en otra preparación estratigráfica (Fig. 3). Debajo de esta muestra aparece un resto de pintura antigua de color rojo,

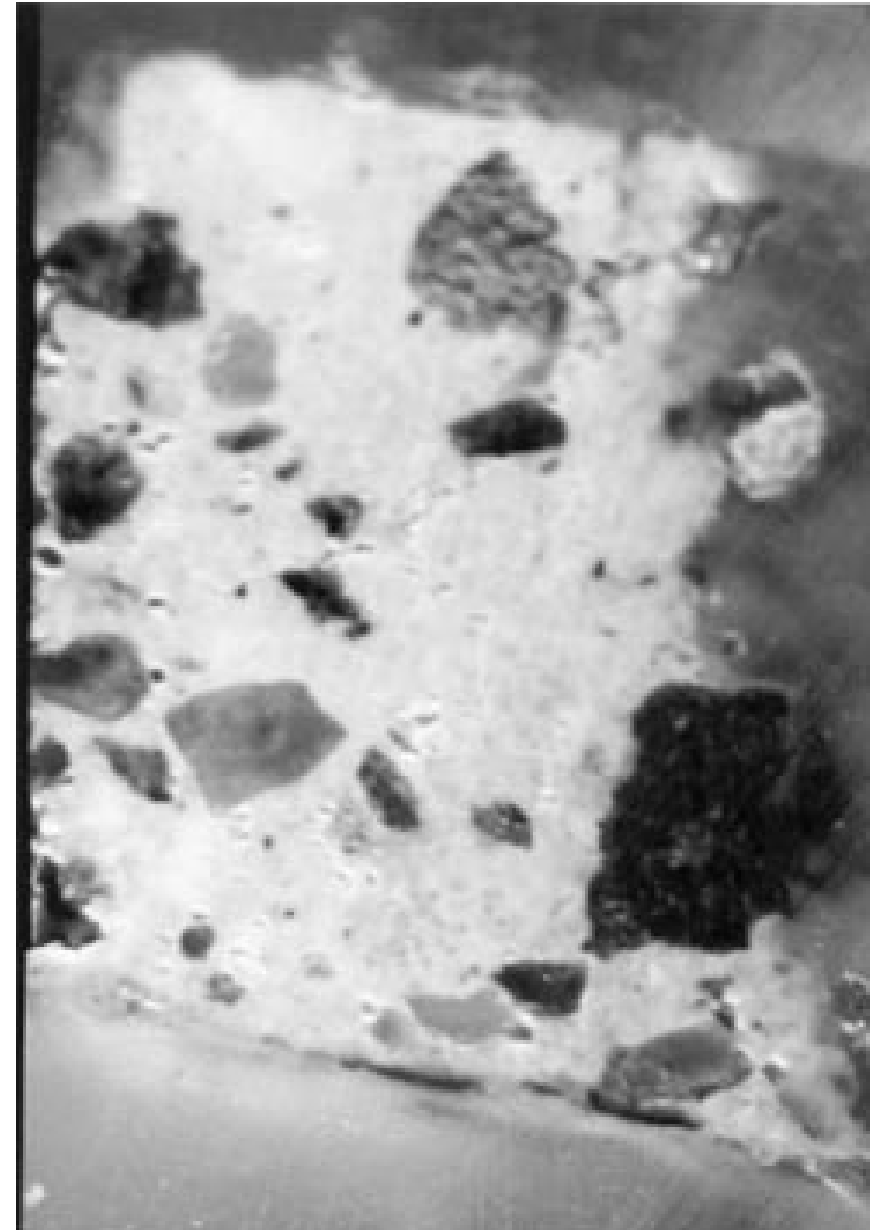

Fig. 2- Preparación estratigráfica correspondiente a la muestra MB2 (x60), capa pictórica de pintura mural gótica de la iglesia de la Anunciación de María (Crngrob, Eslovenia) atribuida al maestro Bolfgang (véase el texto).

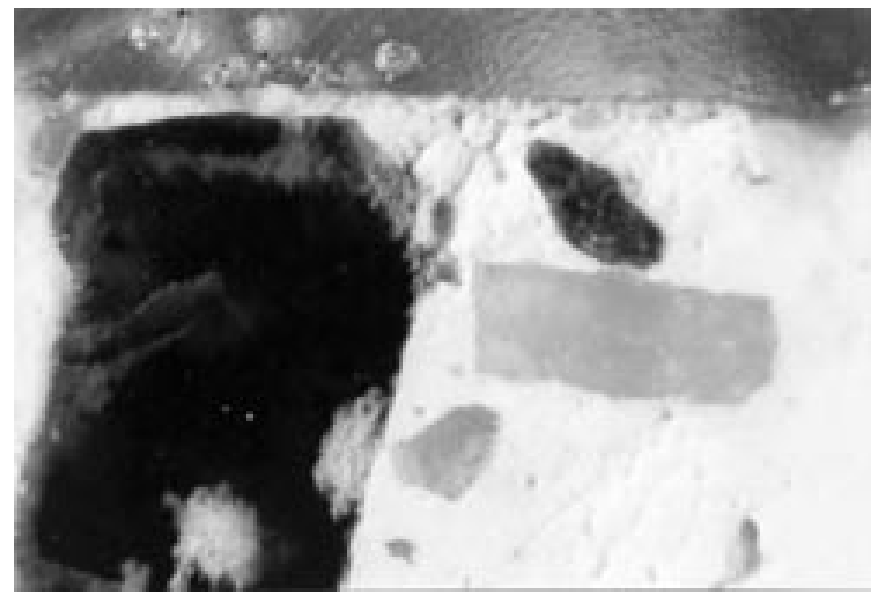

Fig. 3- Detalle de la Fig. 2 (x100), capa pictórica amarilla.

probablemente cinabrio (sulfuro de mercurio).

Como se ha mencionado, los granos blanquecinos que se han observado a través del estudio por microscopía óptica (Fig. 1) son, probablemente, de mármol triturado y mezclado. Mediante análisis de fases cristalinas por DRX (Fig. 4) se ha comprobado la naturaleza del mortero y se ha confirmado esta hipótesis inicial. Las fases cristalinas mayoritarias son 


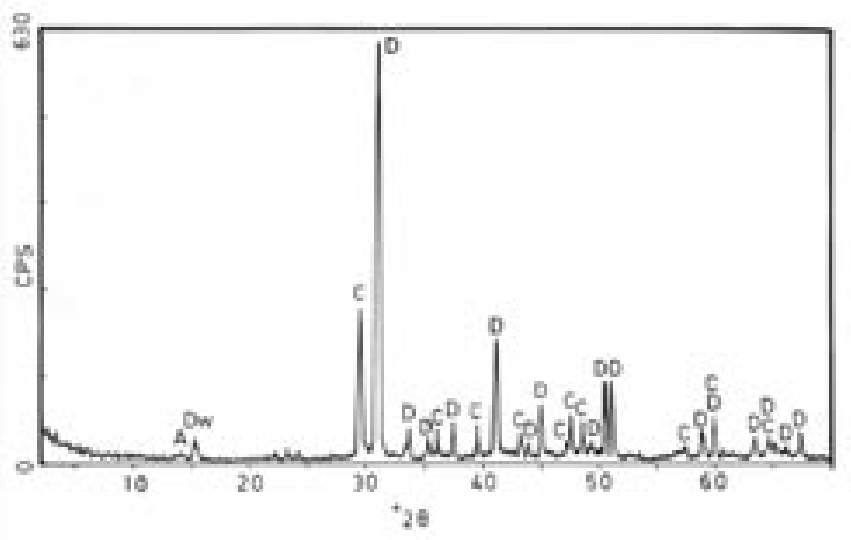

Fig. 4- Diagrama DRX de polvo correspondiente al mortero soporte de la muestra CRG8 con cal y mármol. $\mathrm{D}=$ Dolomita $\mathrm{CaMg}\left(\mathrm{CO}_{3}\right)_{2} ; \mathrm{C}=$ Calcita $\mathrm{CaCO}_{3} ; \mathrm{A}=$ Albita NaAlSi $_{3} \mathrm{O}_{8} ; \mathrm{Dw}=$ Dawsonita $\mathrm{NaAlCO}_{3}(\mathrm{OH})_{2}$. Posiblemente también exista el mineral Trona $\mathrm{Na}_{3} \mathrm{H}\left(\mathrm{CO}_{3}\right)_{2} \cdot 2 \mathrm{H}_{2} \mathrm{O}$ o incluso yeso, identificados pero en muy baja proporción y con difracciones coincidentes con las fases anteriores.
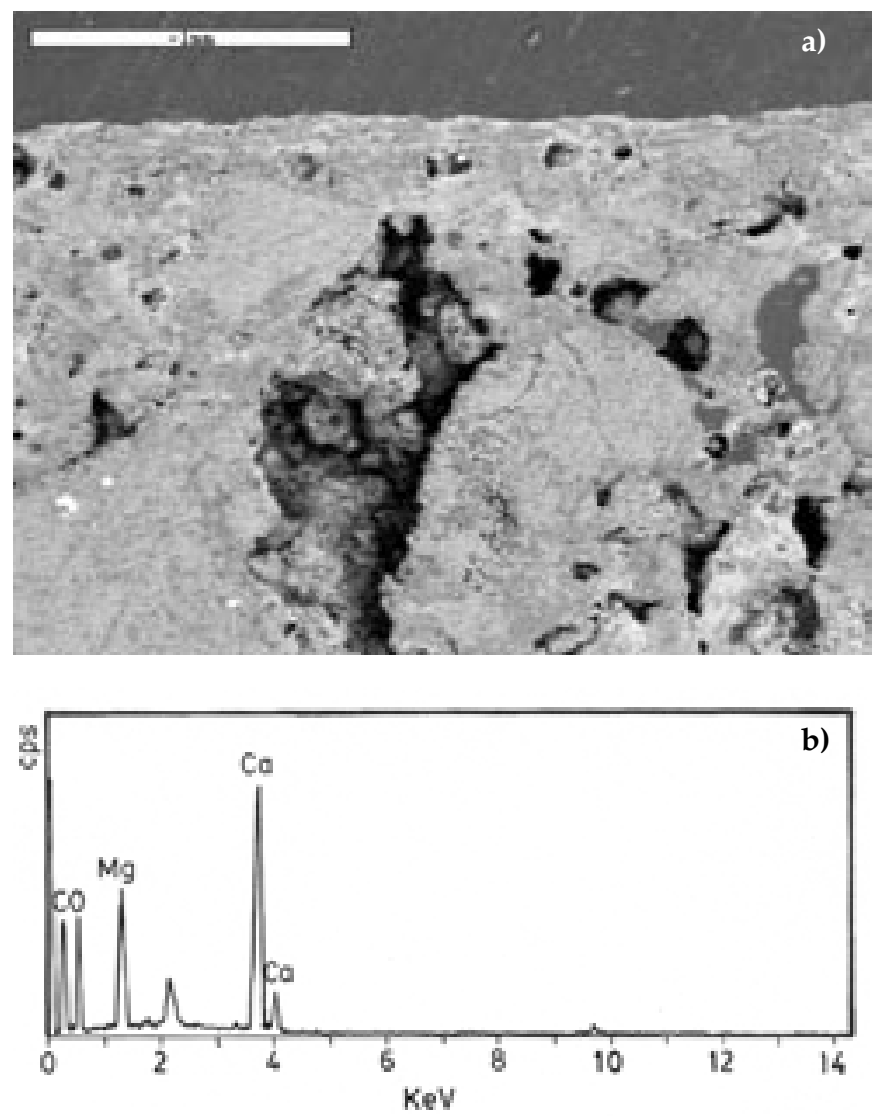

Fig. 5- a) Microfotografía MEB (detalle) correspondiente a la estratigrafía de la Fig.1, muestra CRG8, capa más antigua de la pintura con influencia italiana. Barra $=1 \mathrm{~mm}$; $b$ ) espectro EDX de dicha muestra. El pico sin indicar a $2.2 \mathrm{KeV}$ es de Au del recubrimiento conductor.

dolomita y calcita, junto a fases minoritarias como son albita, dawsonita y, posiblemente, trona. Debajo de esta capa de mortero se encuentra otra, conocida como ariccio, donde se aprecian, además de cal, granos de arena que presentan coloración. También los análisis químicos por

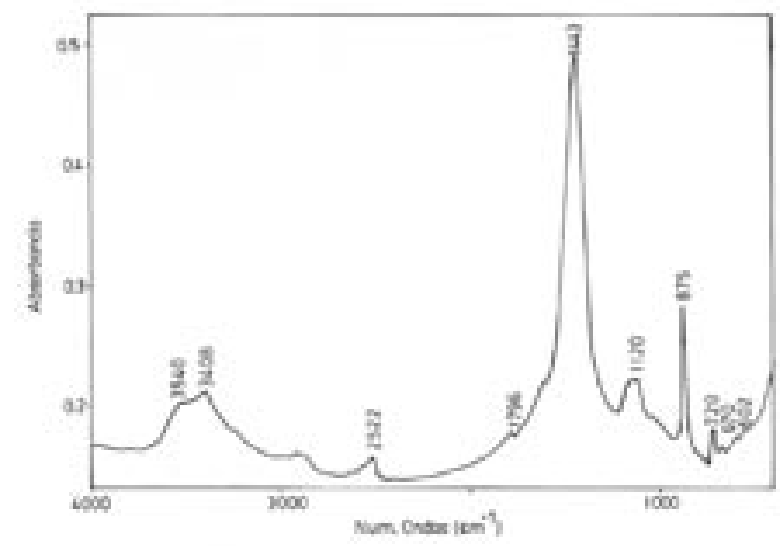

Fig. 6- Espectro IR de la muestra CRG8, representando absorbancia frente a número de ondas $\left(\mathrm{en}^{-1}\right)$. Entendiendo que se atribuyen las bandas a grupos característicos de enlace y que pueden solaparse, las bandas $\mathrm{OH}\left(\mathrm{en} \mathrm{cm}^{-1}\right)$ aparecen 3540 y 3408; bandas atribuidas a la fase mineral calcita a 2522, 1796, 1443 (muy intensa), 875 y 720 , solapando con otras de carbonatos presentes; las bandas a 1120 , 670 y 602 podrían estar asociadas a grupos sulfato (yeso o bassanita $\mathrm{CaSO}_{4} \cdot 0.5 \mathrm{H}_{2} \mathrm{O}$ ) y/o silicatos).
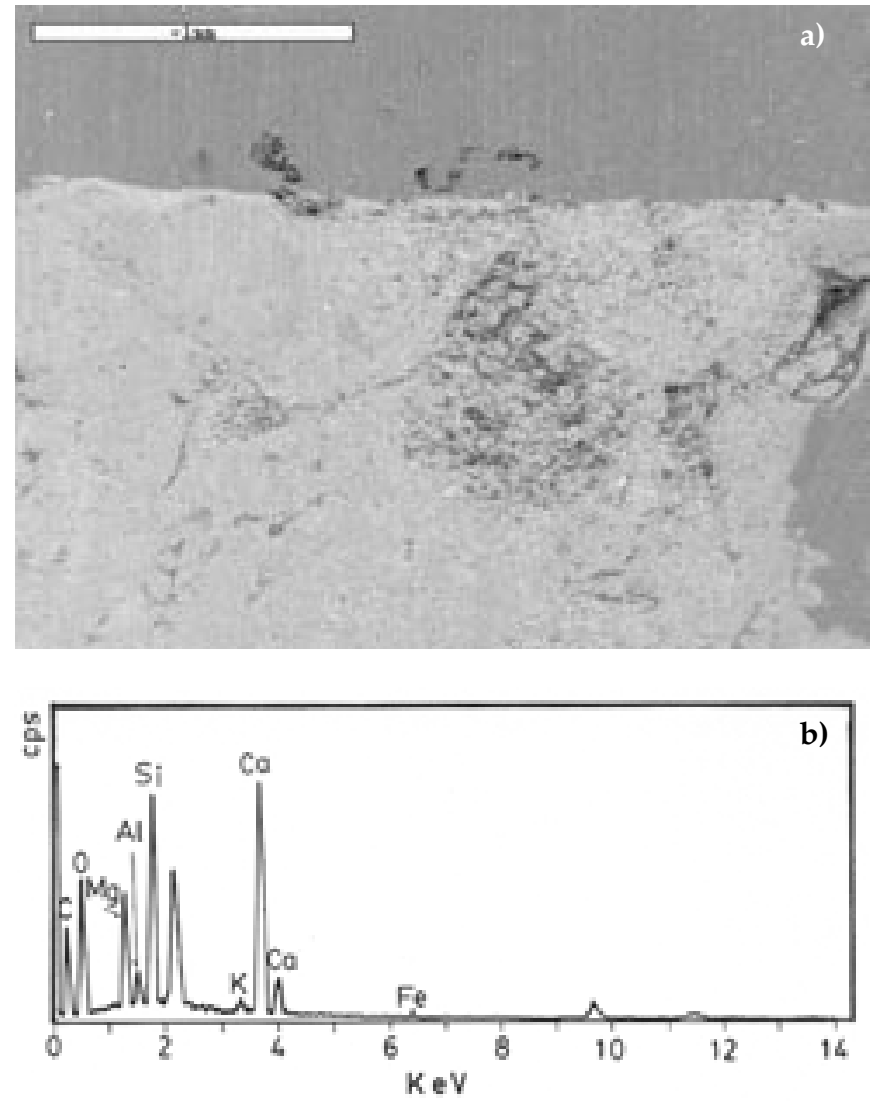

Fig. 7- a) Microfotografía MEB (detalle) correspondiente a la estratigrafía de la Fig. 2, muestra MB2, la parte superior con la capa pictórica amarilla. Pintura perteneciente al maestro Bolfgang. Barra $=1 \mathrm{~mm} ; \mathrm{b}$ ) espectro EDX del mortero soporte de la muestra MB2 (cal y arena silícea). El pico sin indicar a $2.2 \mathrm{KeV}$ es de $\mathrm{Au}$ del recubrimiento conductor.

EDX han comprobado la presencia del elemento Calcio y los resultados obtenidos mediante espectroscopía IR que se han llevado a cabo en este estudio de pigmentos y soportes han demostrado la presencia de silicatos, donde además, 


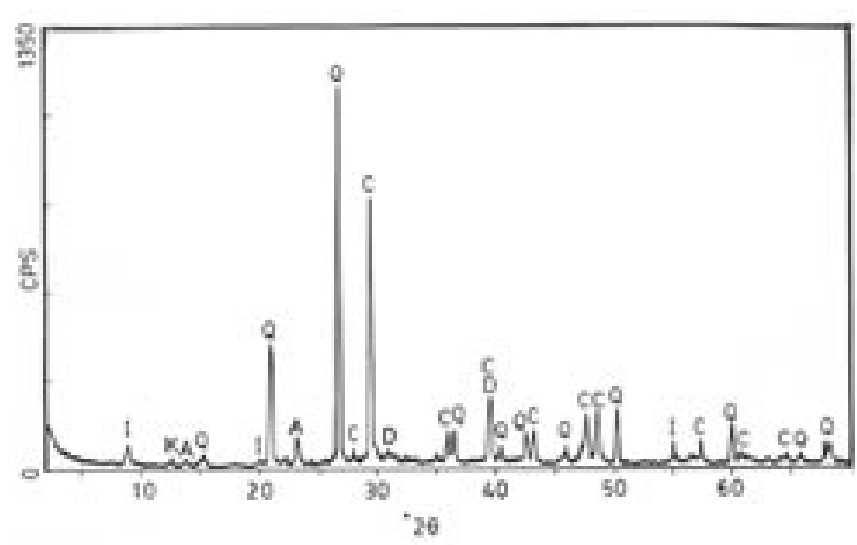

Fig. 8- Diagrama DRX de polvo correspondiente a la muestra MB2. $\mathrm{Q}=$ Cuarzo SiO2; $\mathrm{C}=$ Calcita $\mathrm{CaCO}_{3} ; \mathrm{D}=$ Dolomita $\mathrm{CaMg}\left(\mathrm{CO}_{3}\right)_{2} ;$ $\mathrm{A}=$ Albita $\mathrm{NaAlSi}_{3} \mathrm{O}_{g^{\prime}} \mathrm{I}=$ Illita $\mathrm{K}_{0.5}(\mathrm{Al}, \mathrm{Fe}, \mathrm{Mg})_{3}(\mathrm{Si}, \mathrm{Al})_{4} \mathrm{O}_{10}(\mathrm{OH})_{2} ; \mathrm{K}=$ Caolinita $\mathrm{Al}_{2} \mathrm{Si}_{2} \mathrm{O}_{5}(\mathrm{OH})_{4}$.

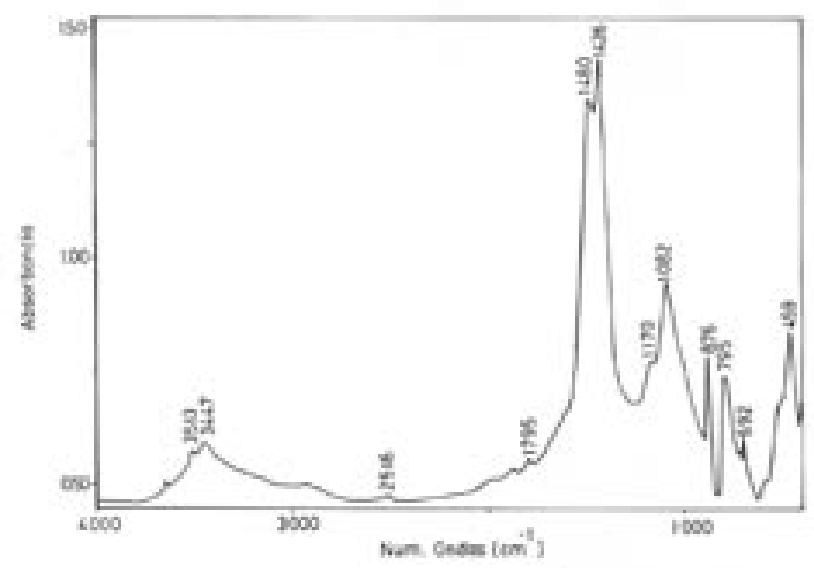

Fig. 9- Espectro IR de la muestra MB2. Bandas OH (en $\left.\mathrm{cm}^{-1}\right)$ en la zona 4000-3000 con bandas atribuidas posiblemente a trona a 3513 y 3447 , junto a la de 1795; calcita a 2516, 1795, 1480 (muy intensa), 1082 y 795; sílice y/o silicatos con bandas a 1426 (muy intensa), 1170, 876, 692 y 459.

destaca la cantidad de carbonato de calcio que serviría de aglutinante (Figs. 5 y 6 ).

Según los resultados de este estudio, el segundo tipo de mortero está realizado con una sola capa, superpuesta a las pinturas de principios del siglo XV, encima de las cuáles pintó el maestro Bolfgang. El mortero está compuesto por cal y granos de arena que por su composición química según los datos de MEB-EDX (Fig. 7) se asemeja al ariccio de la pintura anterior. La comparación con el mortero de la capa más antigua se puede observar también en las Figuras 8 y 9, donde se presentan los resultados obtenidos por DRX y espectroscopía IR. Las fases cristalinas mayoritarias son cuarzo y calcita, a diferencia del otro tipo de mortero, identificándose también la presencia de fases minoritarias, como son dolomita, albita y silicatos laminares, principalmente illita y caolinita (Fig. 8). Es lógico pensar en el uso de arena próxima a la iglesia de Crngrob. Encima de esta capa, el maestro Bolfgang empleaba en algunas partes, como por ejemplo los vestidos, una fina capa de cal que refrescaba el mortero y, además, aumentaba el poder aglutinante de la propia cal componente del mortero. Es muy probable que el pintor utilizara también otros aglutinantes, como yema de huevo, caseína o cola animal para terminar las pinturas en la técnica "a secco". Hasta el momento, no se ha podido demostrar la presencia de ninguna de estas sustancias orgánicas, en contraste con las inorgánicas. Aunque estén presentes, su cantidad es demasiado pequeña para que el equipo de espectroscopía IR del que se dispone pudiera analizarlo y deducir categóricamente su presencia, aunque hay algunos indicios plausibles. Es de interés mencionar que están pendientes análisis de muestras seleccionadas por medio de técnicas instrumentales más sensibles que emplean, por ejemplo, espectrometría de masas. Sin embargo, al recurrir a esa técnica hay que partir de mayor cantidad de muestra para obtener resultados cuantitativos y los análisis son destructivos.

En consecuencia, los resultados experimentales permiten deducir que las pinturas del primer grupo se realizaron a la manera de fresco buono sin otro aglutinante que la cal, mientras que la del segundo grupo se llevaron a cabo en combinación de técnicas "a fresco", "a secco" y "a cal". La última es la técnica pictórica en la cual se pinta encima de una capa fresca de cal y es típica de pintura mural del Norte de Europa. Hay que indicar que ya las pinturas murales romanas presentaban una depurada elaboración técnica, con una serie de capas de preparación del muro hasta llegar a la propia capa pictórica (11-14). Por ejemplo, se empleaban capas de cal y arena de cuarzo y la pintura se llevaba a cabo sobre una última capa de 1 a $3 \mathrm{~mm}$ de espesor (denominada intónaco) que estaba elaborada con cal y polvo de calcita o mármol y con un acabado muy fino. Sobre dicha superficie final aún fresca se podían trazar las líneas maestras del diseño pictórico y su distribución en el muro. Ya en el siglo I d.C., Vitruvio describe el revestimiento ideal que debía ser el soporte perfecto, con seis capas, siendo las tres primeras de cal y arena y las otras tres de cal y polvo de mármol (14). El espesor y los componentes debían ser tanto más finos cuanto más superficiales, pero esta idealidad nunca se alcanzaba: el número de capas oscilaba entre dos y cuatro y en muchas ocasiones, según se ha descrito (14), ni siquiera se aplicó una última muy fina de una masa de cal y calcita o de cal y polvo de mármol muy fino, alisándose la superficie mecánicamente antes de proceder a pintar sobre ella.

Está documentado ampliamente que la técnica al fresco se basa en la aplicación de colores, de preferencia pigmentos minerales en suspensión acuosa o empleando cal apagada (hidróxido de calcio), sobre los enlucidos aún húmedos $(1,2,5,11-14)$. Una vez seco el mortero, los pigmentos forman un conjunto rígido con una alta resistencia al desgaste y al tiempo. Lo que ocurre es el proceso químico de formación de una delgada película de carbonato de calcio $\left(\mathrm{CaCO}_{3}\right)$, originada mediante reacción de la cal apagada (hidróxido de calcio), bien sea del propio enlucido húmedo o empleada como vehículo con los pigmentos, con el dióxido de carbono presente en la atmósfera. La película formada garantiza la conservación de los propios colores que forman el pigmento, su perfecta adherencia y su resistencia a la acción del agua (11-14). En un sentido tradicional se ha denominado pintura al fresco a cualquier pintura mural, pero en sentido estricto sólo debería ser según la técnica descrita anteriormente. Un resultado similar, pero menos duradero, se obtiene aplicando una mano de cal apagada sobre la superficie que se va a pintar y aplicando sobre ella los pigmentos dispersos en agua; o también pintando con estos pigmentos, diluidos 
en agua de cal, sobre un enlucido ya seco (14).

En relación a la presente investigación, el estudio físicoquímico y mineralógico de pinturas y revestimientos murales de época romana realizado en la pasada década de los setenta por García Ramos y cols. $(11,12)$, que incluyen sucinta bibliografía de los estudios de este tipo llevados a cabo en otros países, ha revelado algunas de estas particularidades y la gama de pigmentos utilizados que no se apartaban mucho de los empleados en época medieval. En estudios posteriores sobre enlucidos y pinturas medievales del monasterio de Santa María de la Rábida (Moguer, Huelva), segunda mitad del S. XV, realizados por Pinilla y García Ramos (13), se ha arrojado más luz sobre las características de los soportes y pigmentos utilizados en esa época. Así, en revestimientos pictóricos de La Rábida (S. XV) no ha sido posible distinguir el soporte del mortero; aquél, en caso de existir, se reduciría a una capa extremadamente delgada. Merece la pena resaltar estos trabajos (11-14) como antecedentes de las primeras investigaciones Arqueométricas en nuestro país, en particular sobre revestimientos murales y pinturas, tanto de época romana como medieval.

Con respecto a pinturas medievales del periodo gótico, son de resaltar las realizadas en el Monasterio de San Isidoro del Campo de Sevilla (15). Muchas de las pinturas murales están realizadas al fresco sobre mortero de cal y arena conteniendo carbonato cálcico (calcita o mármol), ya que así aumentaba la calidad y dureza de la capa superficial. Se añadía también una proporción de fibra vegetal, formando un verdadero material compuesto (composite) que aportaba cierta elasticidad al mortero. Las pinturas de la zona del arrimadero (1431-1436) de este monumental edificio, a juicio de los expertos (15), debido a su“alta calidad, la expresividad de los personajes y la sensación de volumen que adquieren en los paños han hecho pensar en la posible intervención de un autor italiano, dada su clara vinculación estilística con obras toscanas de la época y detectándose también la influencia del Gótico Internacional". Se ha apuntado incluso a la autoría del llamado Maestro de los cipreses, autor de miniaturas de los libros de coro de la Catedral de Sevilla y que se podría identificar como Pedro de Toledo. En otras zonas de este Monasterio, las pinturas murales del S.

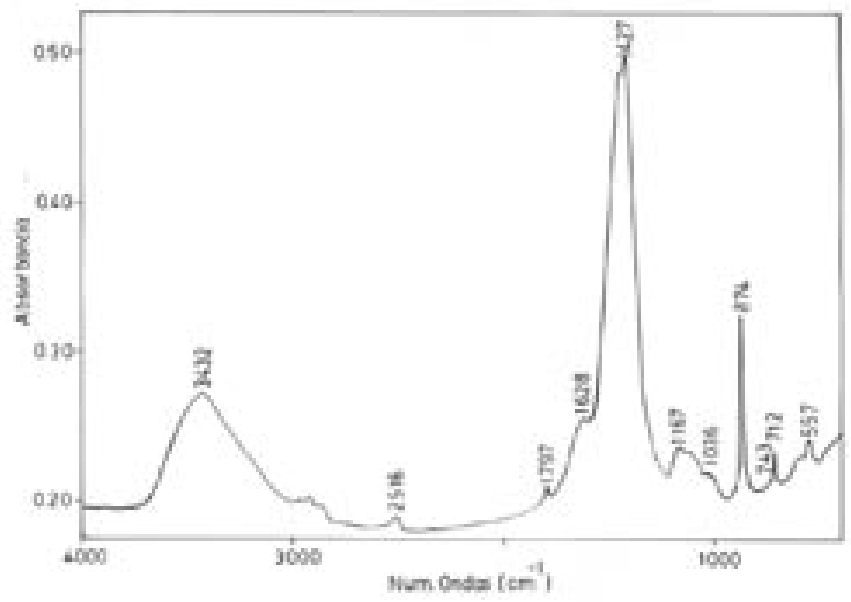

Fig. 10- Espectro IR del pigmento verde que se ha identificado en las pinturas murales góticas. Bandas $\left(\mathrm{en}^{-1}\right.$ ) a 3432 (ancha), atribuida a grupos $\mathrm{OH} ; 1628,1036,743$ y 557 atribuidas a mica illita; bandas a 2516, 1796, 1427 (muy intensa), 874 y 712, atribuidas a calcita. En definitiva, calcita y silicatos.
XV son representaciones de carácter monumental únicas en España. Estilísticamente, está clara su relación con el arte italiano y el Gótico Internacional, atribuyéndose a un pintor de procedencia florentina (15). Esta problemática de autoría también la encontramos en las pinturas murales góticas objeto del presente estudio, pero en todo caso los estados de conservación no son comparables y se requieren investigaciones posteriores.

Por otra parte, es importante mencionar que en ninguna muestra con capa pictórica verde estudiada en el presente trabajo se ha encontrado malaquita (carbonato básico de cobre) que también se empleaba en la época como pigmento verde. Se trata de lo que se denomina una "tierra verde", cuyo espectro IR y análisis químico por EDX se presentan en las Figuras 10 y 11, respectivamente. El estudio de las bandas características demuestra la presencia de carbonatos y silicatos, asociados a dicha "tierra verde" utilizada como tal pigmento. Es de resaltar que los resultados obtenidos por EDX (Fig. 11) indican la presencia de elementos característicos en esta tierra verde, como son silicio, magnesio, aluminio, posiblemente azufre, calcio, hierro y potasio. Por ejemplo, se conocen pigmentos denominados "tierra verde veronesa", "tierra verde italiana genuina" y "tierra verde

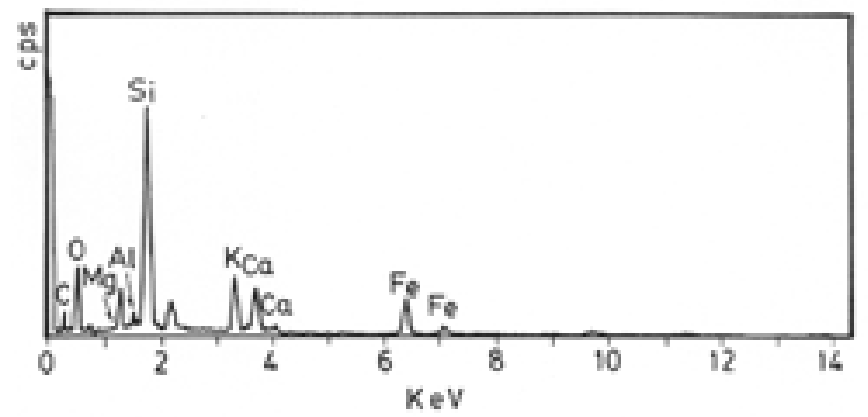

Fig. 11- Espectro EDX del pigmento verde. El pico sin indicar a 2.2 $\mathrm{KeV}$ es de $\mathrm{Au}$ del recubrimiento conductor.

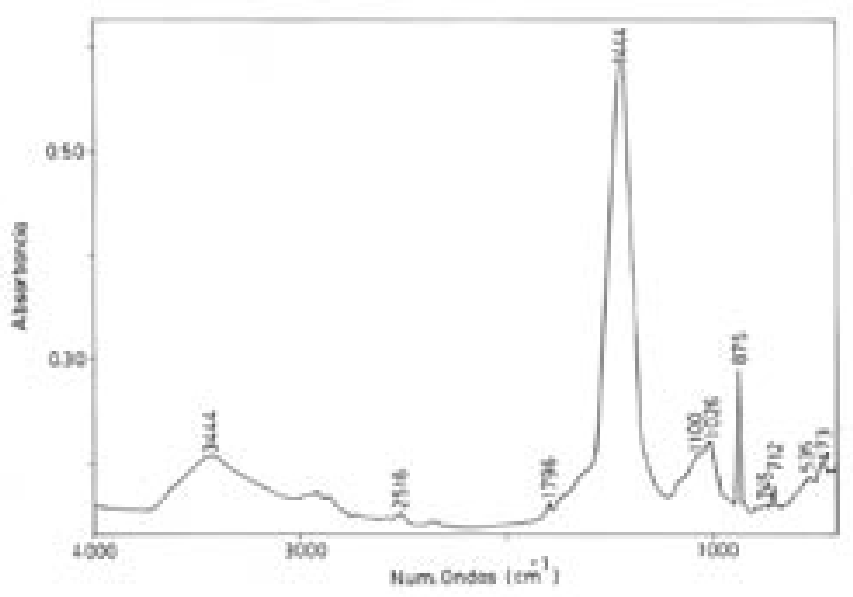

Fig. 12- Espectro IR correspondiente al pigmento amarillo, identificado como "tierra ocre". Bandas $\mathrm{OH}\left(\mathrm{en} \mathrm{cm}^{-1}\right)$ en la zona entre 4000 y 3000 , con banda a 3444 atribuida a mica illita, además de la que se detecta a 1026, 745, 534 y 473; las bandas a 534 y 473 también se asocian a hematites posiblemente presente; las bandas a 2516,1796, 1444 (muy intensa), 875, 712 atribuidas a carbonatos, con toda probabilidad calcita; la banda a 1100 propia de silicatos. En definitiva, óxidos de hierro, silicatos y carbonatos. 


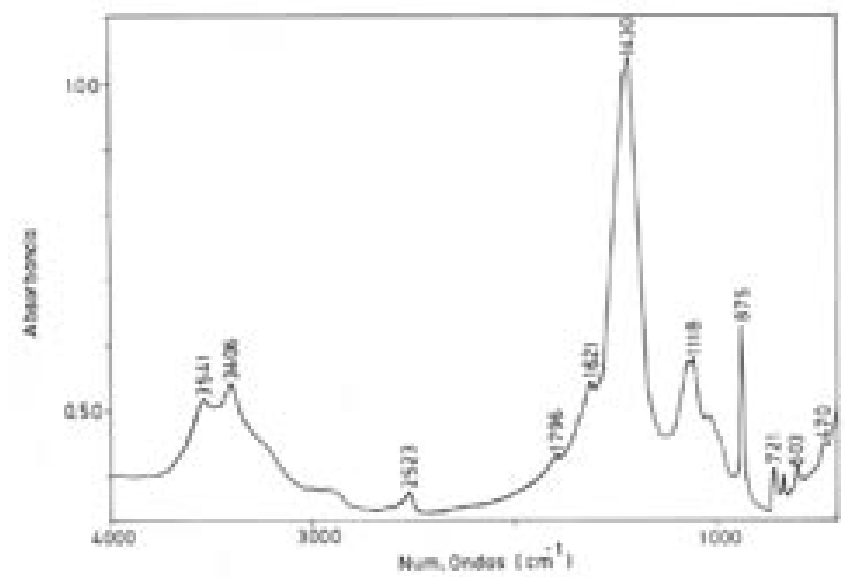

Fig. 13- Espectro IR correspondiente al pigmento rojo, denominado también "tierra roja" o "ocre quemado", muy similar al espectro IR

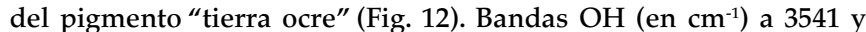
3406 , posiblemente también asociadas a la presencia de yeso, junto a las bandas a 1621, 1118 y 603; bandas de calcita a 2523, 1796, 1430 (muy intensa), 875 y 721; posiblemente, las bandas IR a 1020, 1118 y 470 estén asociadas a silicatos presentes, y esta última banda solapada con la asociada a óxidos de hierro (hematites).

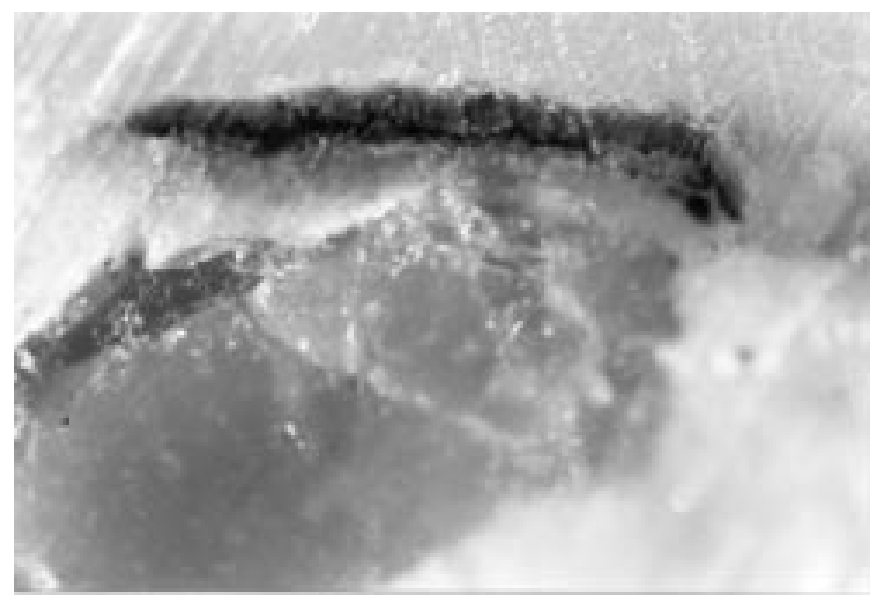

Fig. 14- Detalle de la muestra de la Fig. 2 (x100), capa pictórica de abajo, con pigmento rojo (identificado como cinabrio, $\mathrm{HgS}$ ).

italiana Brentónico genuina", entre otras "tierras verdes", que contienen silicatos laminares y suelen emplearse como pigmentos englobados dentro de la categoría de pigmentos de Tierras Naturales (16).

En cuanto al pigmento amarillo, se puede afirmar que se trata de ocre amarillo: los ocres son óxidos de hierro, lo que indica la espectroscopía IR (Fig. 12) pero asociado con carbonatos y silicatos, de acuerdo con las bandas que aparecen utilizando esta técnica. El pigmento rojo es ocre quemado, también de naturaleza óxido de hierro, tal como indican los resultados obtenidos por espectroscopía IR (Fig. 13). Con los análisis realizados se ha comprobado que en todas las pinturas se aplicaron pigmentos apropiados para la pintura mural, como son óxidos de hierro para amarillo, naranja, rojo e incluso verde.

Asimismo, en las capas más antiguas de estas pinturas murales góticas se utilizó también cinabrio para el color rojo (véase Figs. 2 y 14, estratigrafías). En algunas partes

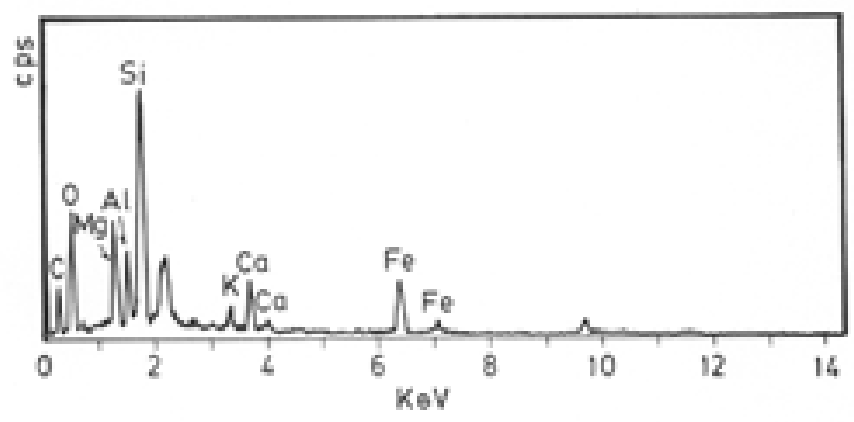

Fig. 15- Espectro EDX de la “tierra roja” analizado por IR (Fig. 13). El pico sin indicar a $2.2 \mathrm{KeV}$ es de Au del recubrimiento conductor.
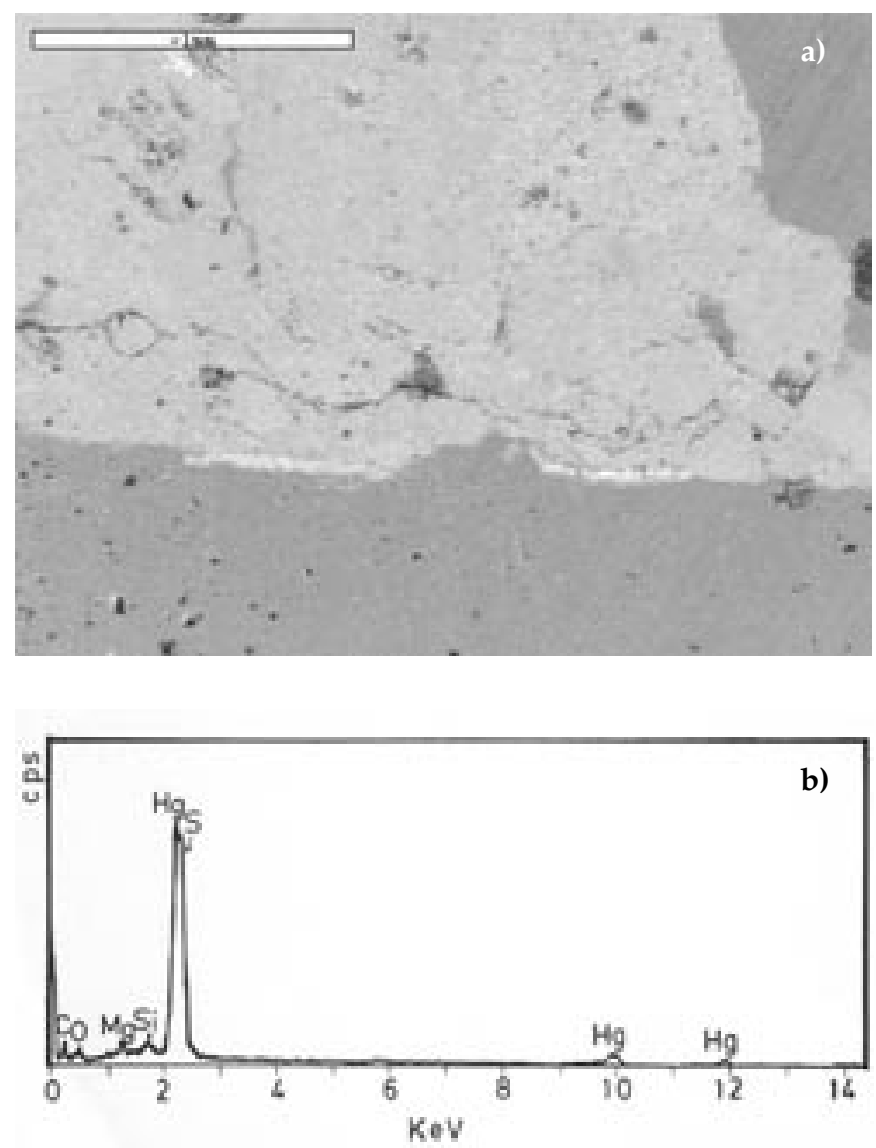

Fig. 16- a) Microfotografía MEB (detalle) de la muestra MB2, parte de abajo de la preparación estratigráfica, donde aparece el otro pigmento rojo analizado por EDX. Barra $=1 \mathrm{~mm}$; b) espectro EDX de dicho pigmento rojo, identificado como cinabrio (HgS). En este caso particular, el pico a $2.2 \mathrm{KeV}$ de Au del recubrimiento conductor solapa con el de azufre (S).

se convirtió en negro a causa de una reacción química por efecto de la exposición a la luz, la humedad y el tiempo. Sin embargo, según los resultados obtenidos en otra muestra estudiada, el pigmento negro utilizado es de naturaleza orgánica y muy probablemente carbón (obtenido de madera o negro de humo). A título de ejemplos, en las Figuras 15 y 16 se presentan los análisis EDX que corresponden a dos zonas diferentes de la capa roja que se encuentra debajo de la atribuida al maestro Bolfgang (Fig. 16a, microfotografía MEB). El primer espectro EDX (Fig. 15) pone en evidencia 
elementos químicos característicos de una composición que contiene silicatos, carbonatos y óxido de hierro, mientras que el otro (Fig. 16b) demuestra la presencia de mercurio y azufre. Es posible que el pintor mezclara dos pigmentos de color rojo (óxidos de hierro y cinabrio) para conseguir el tono adecuado que deseaba. La presencia de plata como elemento identificado en otro espectro EDX todavía no se ha podido explicar, hasta el momento, de una forma satisfactoria.

El cinabrio o bermellón claro es el sulfuro de mercurio (HgS), que cuando es puro o bien se ha procedido a un cuidadoso proceso de depurado, presenta un color rojo vivo intenso de excelente belleza. En tiempos antiguos, al cinabrio se le conocía como minium y fue muy utilizado en las pinturas de Pompeya $(1,12,14,15)$. Al ennegrecer este compuesto cuando se expone al sol, debido a la acción de los rayos ultravioletas, los romanos daban cera a las superficies murales pintadas con cinabrio para atenuar o paliar este efecto (16). Se emplea generalmente como color al óleo para evitar decoloraciones, habiendo sido utilizado por pintores de la talla de Piero della Francesca, Boticelli, Rafael, Tiziano, Rubens, Zurbarán, Rembrandt, Renoir, Cézanne, Monet, Manet, etc. Muy recientemente, ha sido utilizado este pigmento en las pinturas al fresco de la Catedral de la Almudena en Madrid, decoración realizada por el artista Kiko Argüello y su equipo (17).

\section{CONCLUSIONES Y CONSIDERACIONES FINALES}

De los análisis realizados por diversas técnicas instrumentales, resumidos en el presente trabajo, y de los antecedentes previos, se puede concluir que los dos grupos de muestras estudiadas clasifican, a su vez, a dos formas de pintura mural existentes en territorio esloveno. La primera es típica para pintura italiana gótica -fresco buono- sobre varias capas de mortero, con empleo de polvo de mármol o calcita previamente triturados en intónaco para hacerlo más blanco y liso. Las pinturas fueron hechas sin empleo de otro aglutinante que la propia cal proveniente del mortero. También el uso del mineral cinabrio (sulfuro de mercurio) como pigmento rojo es típico de Italia. Esto sitúa las pinturas del 1400-1410 que se han estudiado en este trabajo, también desde el punto de vista técnico, en la corriente artística italiana del Trecento. La segunda forma de pintura mural gótica es típica del norte de Europa: técnica de una o dos capas de mortero, con una capa fina de cal superpuesta para dar mayor fuerza a la cal del mortero como aglutinante. Normalmente se utilizaban también otros aglutinantes orgánicos para los pigmentos.

Los dos tipos de muestras estudiadas en este trabajo, cuyos análisis han facilitado el conocimiento de sus características particulares, han permitido demostrar que las dos corrientes europeas, la italiana y la norteeuropea, se encontraron en el territorio esloveno. Con la contribución del presente estudio multidisciplinar, además de apreciarlo desde el punto de vista estilístico, se ha posibilitado comprobarlo también científicamente.

En la actualidad, es de destacar que se encuentra ya evaluado y aprobado un Proyecto conjunto entre la República de Eslovenia (muy recientemente miembro de la UE) y el Reino de España para profundizar y proseguir las investigaciones científicas y técnicas sobre pinturas murales góticas, iniciadas en este trabajo, en el marco de la cooperación cultural bilateral (Ministerios de Asuntos
Exteriores). Los resultados que se están obteniendo permiten apreciar diferencias entre morteros de distintos talleres pictóricos, tipos de pigmentos utilizados por los pintores del gótico y la técnica que prevalecía en la pintura mural. En consecuencia, con el desarrollo y culminación de este Proyecto se podrán estudiar en profundidad, conocer sus paralelismos con las pinturas góticas españolas y establecer su importancia dentro del contexto Europeo

\section{AGRADECIMIENTOS}

Se agradece la financiación recibida al Proyecto de investigación MAT2002-02549, mencionando que está cofinanciado en parte con Feder, en el marco del cual se ha realizado este trabajo. Asimismo, se agradece al Ministerio de Asuntos Exteriores de España por la Beca 2002-2003 concedida a Anabelle Kriznar, a la Junta de Andalucía, Grupo TEP204 (III Plan Andaluz de Investigación) que ha facilitado iniciar este estudio y a la Red Temática RTPHC del CSIC. Los autores desean expresar su gratitud al Dr. M.A. Avilés Escaño, al Ingeniero E. Jiménez Roca y la Lda. $\mathrm{M}^{\mathrm{a}}$. C. Jiménez de Haro por su contribución en la parte experimental del trabajo, así como a la Dra. M. Arjonilla Alvarez por su valiosa aportación sobre pigmentos antiguos en la discusión de resultados.

Los autores quieren dedicar este trabajo al Dr. D. Guillermo García Ramos, Investigador Científico del CSIC, ya retirado por imperativo legal, por su gran calidad humana, entusiasmo y reconocimiento por su contribución científica al inicio de los estudios de Arqueometría en Andalucía y en nuestro país.

\section{BIBLIOGRAFÍA}

1. R. Mayer, "Materiales y técnicas del arte”, Edit. Hermann Blume, 687 pp., Madrid, 1988.

2. M. Matteini y A. Moles, “La chimica nel restauro. I materiali dell'arte pittorica", Edit. Nardini, 379 pp. Roma, 1989.

3. J.M. Albella, A.M. Cintas, T. Miranda y J. Ma Serratosa (Coordinadores), "Introducción a la Ciencia de Materiales", Textos universitarios, CSIC, Madrid, 1993.

4. J. Castaing, “Observaciones y análisis de objetos de Patrimonio", p. 9597 en Temas actuales en Ciencia de Materiales, Homenaje a D. Rafael Márquez Delgado (A. Conde, A. Domíguez y J. Leal, eds.), Universidad de Sevilla, Secretariado de Publicaciones. Sevilla, 2000.

5. M. Matteini y A. Moles, "Ciencia y Restauración. Método de investigación”, Ed. Nerea, Junta de Andalucía, Consejería de Cultura, Instituto Andaluz del Patrimonio Histórico. Bilbao, 2001.

6. B. Gómez, M.A. Respaldiza y Mª. L. Pardo (eds.), “III Congreso Nacional de Arqueometría", Serie Colección Abierta número 50. Secretariado de publicaciones, Universidad de Sevilla. Sevilla, 2001.

7. Kriznar A., "The youngest layer of mural painting in Selo in Prekmurje", Zbornik Soboskega muzeja, VI, Murska Sobota 2001, pp. 7-26.

8. Kriznar A.,"The influence of southern-tyrol art on the work of 'northstyrian duke workshop' in St. Ruprecht and in St. Lorentz in the valley of the river Mürz in the Northern Styria", ZUZ, n.v., núm. 38, Ljubljana, 2002.

9. J. Höfler, "Middle-Age Paintings in Slovenia", Ed. Gorenska. Ljubljana, 1996.

10. E. Jiménez Roca, A. Ruiz-Conde y P.J. Sánchez-Soto, “Preparación de secciones estratigráficas. Aspectos prácticos del análisis de estratos en obras del Patrimonio Cultural", Bol. Soc. Esp. Ceram. V., 44 [6] 382-386 (2005).

11. G. García Ramos, A. Justo y L. Abad Casal, "Estudio físico-químico y mineralógico de una serie de pinturas y revestimientos murales de Itálica (Sevilla)", Archivo Español de Arqueología, 49, 141-152 (1976).

12. G. García Ramos, M.D. Linares López y L. Abad Casal, “Estudio físicoquímico y mineralógico de algunas muestras de pinturas y revestimientos murales de Bolonia (Cádiz)", Archivo Español de Arqueología, 50-51, 295-310 (1978).

13. E. Pinilla y G. García Ramos, “Pinturas medievales de La Rábida. Su 
conservación. Estudio físico-químico y mineralógico de muestras de pintura medieval de La Rábida (Huelva)", 76 pp. Huelva, 1976.

14. L. Abad Casal, "Pinturas romanas en la provincia de Sevilla”, Colección Arte Hispalense, Editado por la Excelentísima Diputación Provincial de Sevilla, Gráficas del exportador, Jerez de la Frontera (Cádiz), 148 p., 1976.

15. P.J. Respaldiza y J.L. Ravé Prieto, “Monasterio de San Isidoro del Campo. Guía. Santiponce (Sevilla), 2002", Junta de Andalucía, Consejería de Cultura, Escandón Impresores, 95 p., Sevilla, 2002.

16. E. Alvarado y C. Sánchez, "Conservación y Restauración artística. Prontuario y Catálogo de Productos CAREMI pigmentos", $1^{\text {a }}$ Edición, Editado por CAREMI Pigmentos, 281 pp., Sevilla, 2001

17. J.F. Ferrer, "Así se pintó la Catedral de la boda", Magazine El Mundo, ${ }^{\circ}$ 240, 14-19, 2004. Nota: en este artículo se menciona que se preparan los colores utilizando "...pigmentos minerales (óxidos) y material especial como la tierra de Siena. El más extraño (sic) y caro es el cinabrio (sulfuro de mercurio), que -cuando se consigue- se paga a unos 600 euros el kilo. En la Catedral de la Almudena se han usado tres kilos. Estos materiales se mezclan cuidadosamente con aceite de linaza, siguiendo técnicas de la Edad Media y se aplican sobre una base de estuco romano, compuesto de cal apagada, aglutinante y polvo de mármol (marmolina), que una vez secado tiene una gran solidez. Con esta técnica, el aceite penetra en el estuco y deja fuera una lámina formada por el colorante mineral. Pasados 20 años, tiempo en el que las pinturas se van secando, se produce un equilibrio (sic) entre el aceite y el pigmento, quedando la pintura fijada y con la garantía de una gran duración".

Recibido: 28.03.05

Aceptado: 12.12 .06 